\title{
Erratum to: Biostratigraphy and paleoecology of Upper Paleocene to Lower Oligocene deposits in Southeast of the Hajiabad Area (Zagros Basin, SW Iran)
}

\author{
Fatemeh Hosseinipour $^{1}$ • Mohammad Javad Hassani ${ }^{2}$
}

Published online: 13 June 2015

(C) Saudi Society for Geosciences 2015

Erratum to: Arab J Geosci

DOI 10.1007/s12517-015-1778-7

The original version of this article, regrettably, contained errors.

Several images did not match with the correct caption and number. All correct figures and plates are given in this paper.

The online version of the original article can be found at http://dx.doi.org/ 10.1007/s12517-015-1778-7. Mohammad Javad Hassani
mj.hassani@mail.kgut.ac.ir

1 Department of Geology, Payame Noor University of Kerman, Kowthar Bil, Kerman, Iran

2 Department of Ecology, Institute of Sciences and High Technology and Environmental Sciences, Graduate University of Advanced Technology, End of Haftbagh Highway, Pardis Danesh Mahan, Kerman, Iran 

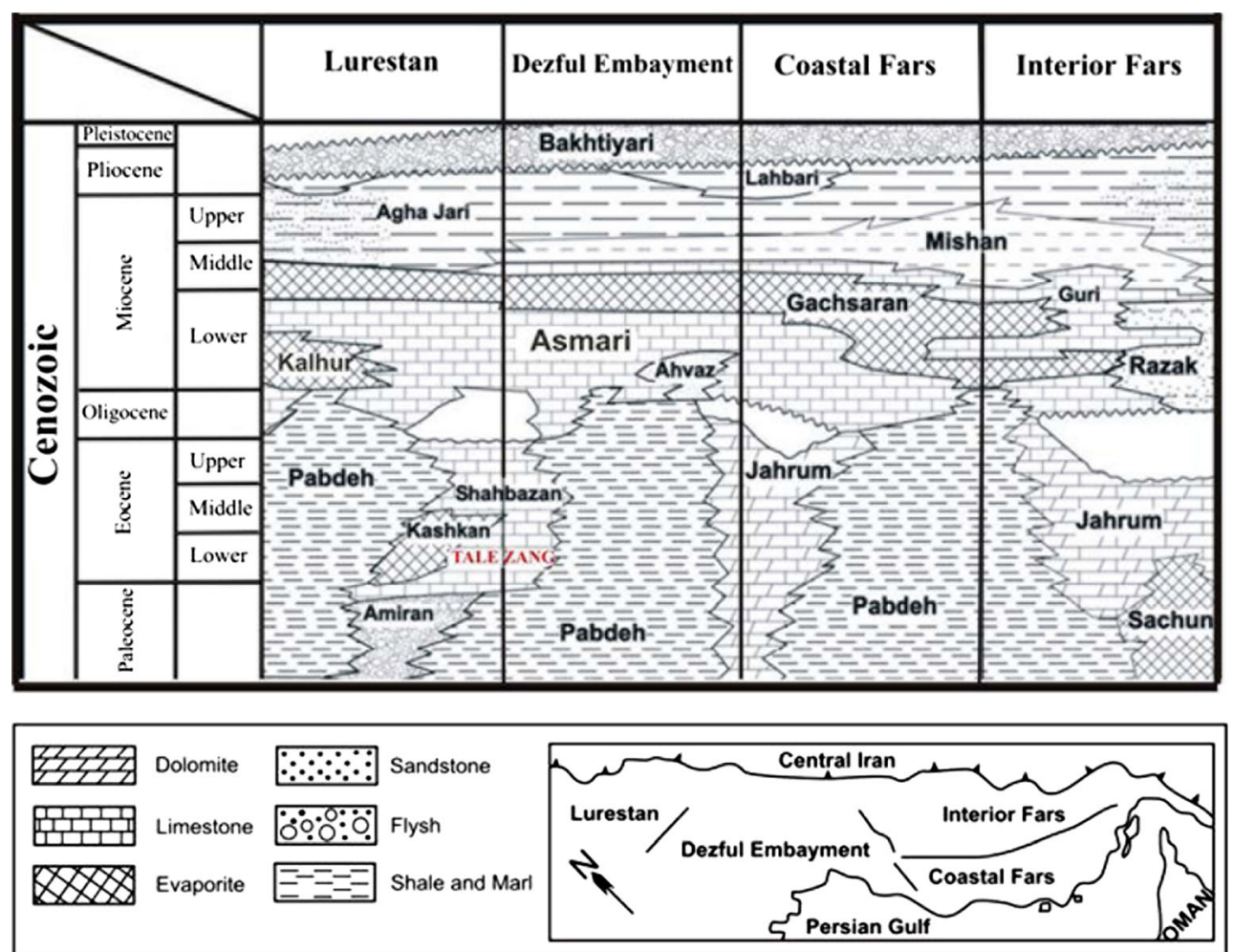

Fig. 1 Correlation chart of the Cenozoic deposits of southwest Iran, adopted from Ala, (Ala 1982) 


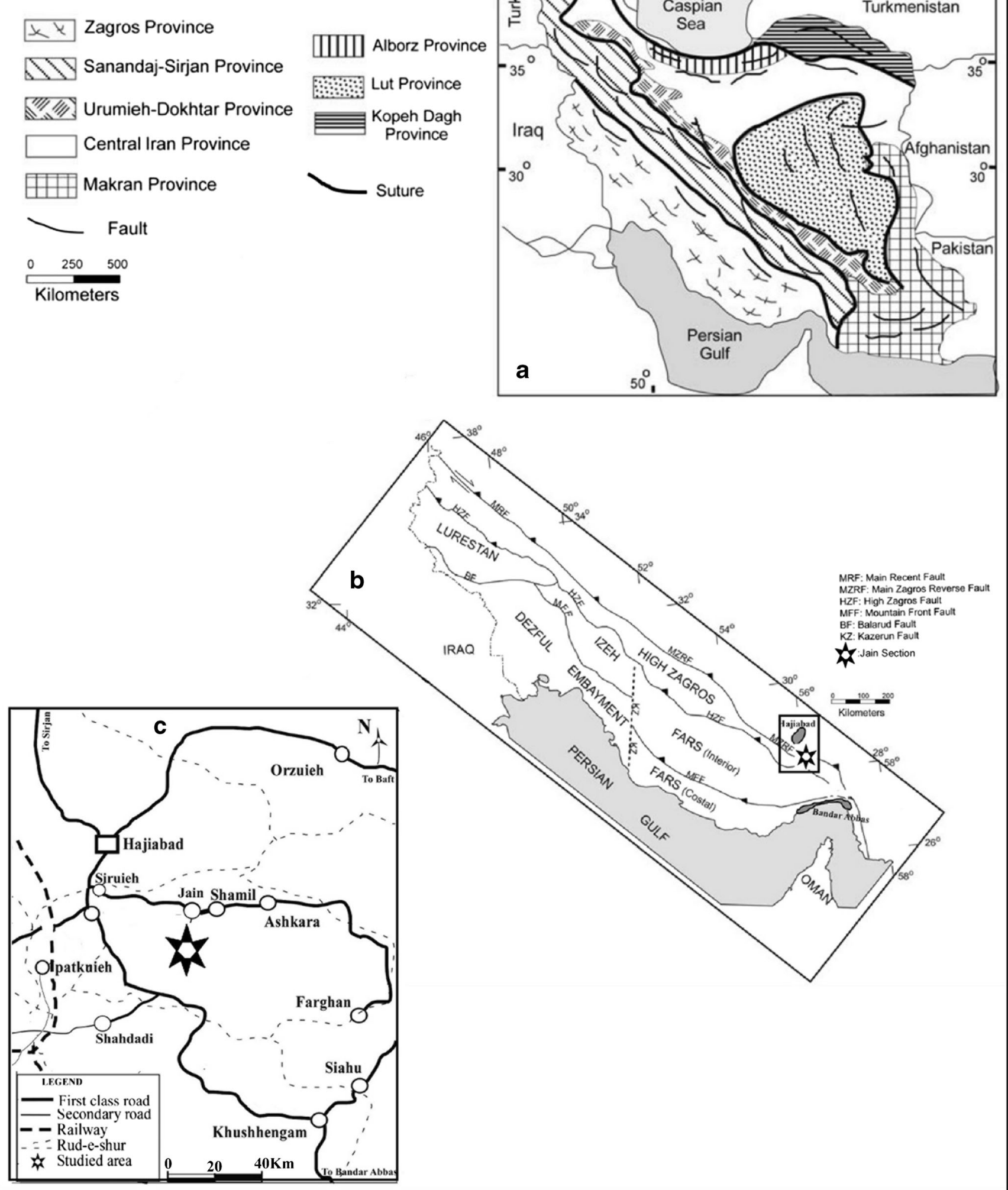

Fig. 2 Location of the studied section in the southeast of the Hajiabad area, southwest Iran (a: Structural divisions of Iran, b: the Zagros Structural Zone and its subdivisions, c: the access map of the Jaein section) 


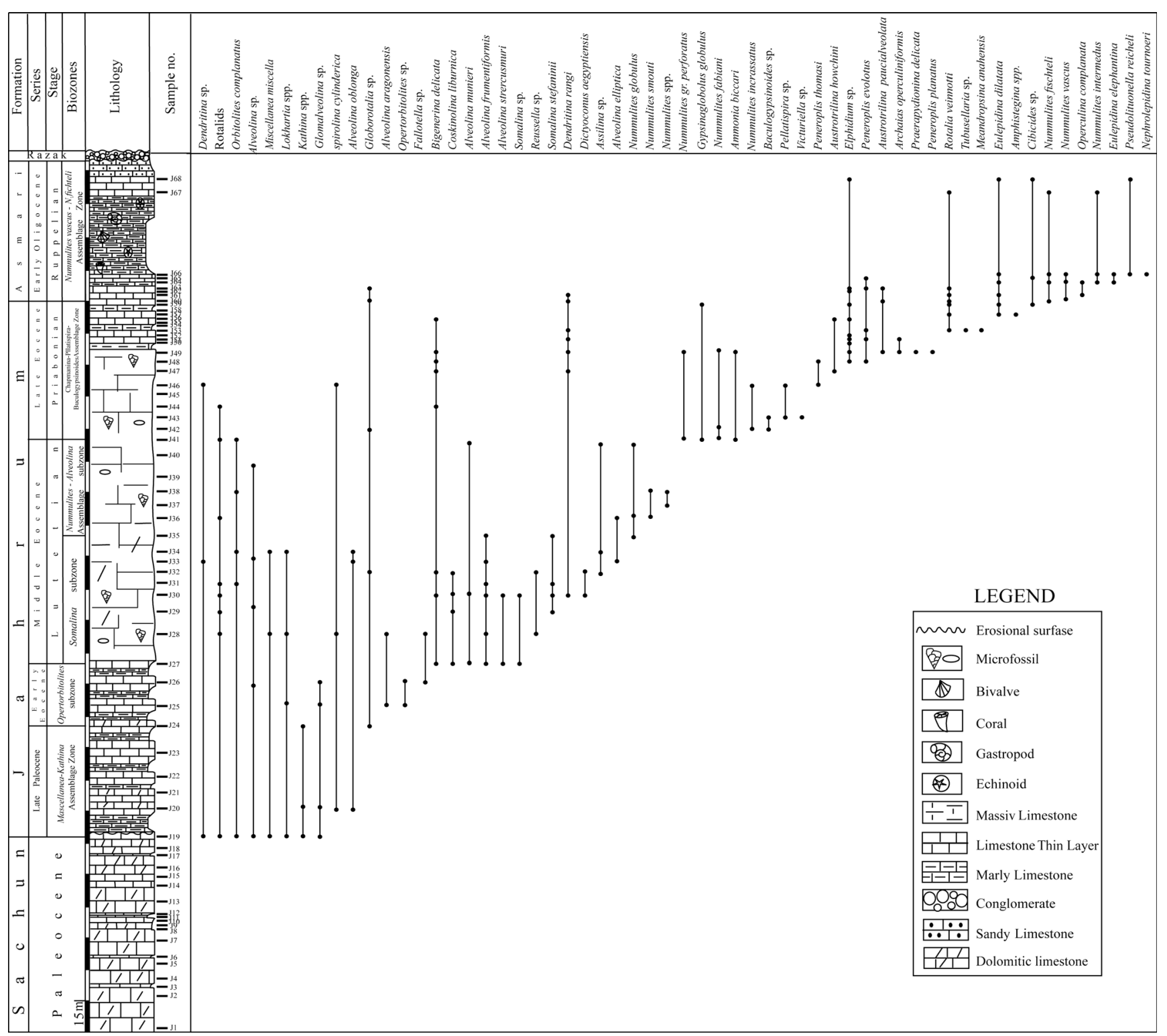

Fig. 3 Distribution of Identified Foraminifera in the Jaein Section during the Paleocene to Oligocene 

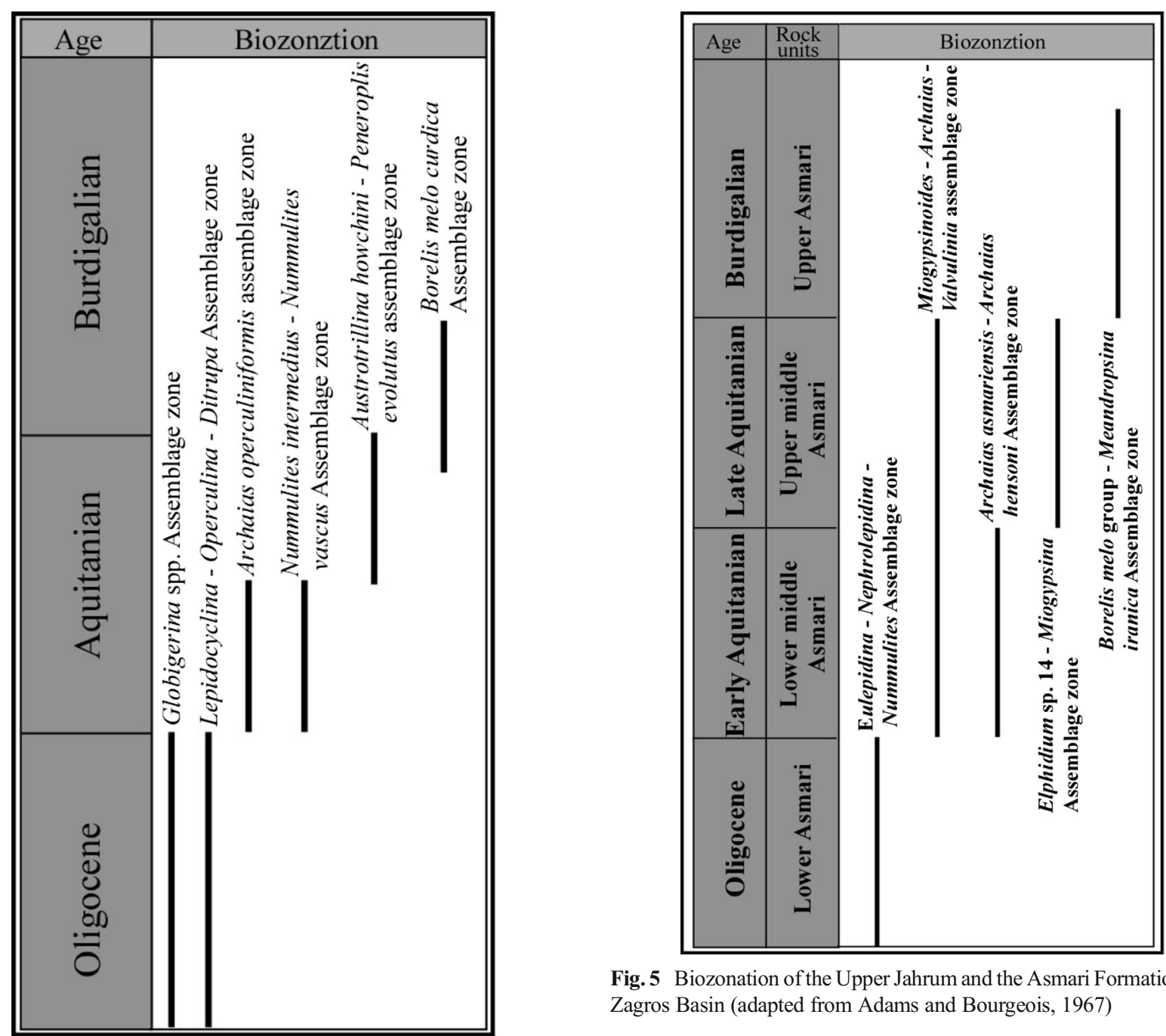

Fig. 5 Biozonation of the Upper Jahrum and the Asmari Formation in the Zagros Basin (adapted from Adams and Bourgeois, 1967)

Fig. 4 Biozonation of the Jahrum Formation (Adapted from Wynd, 1965) 


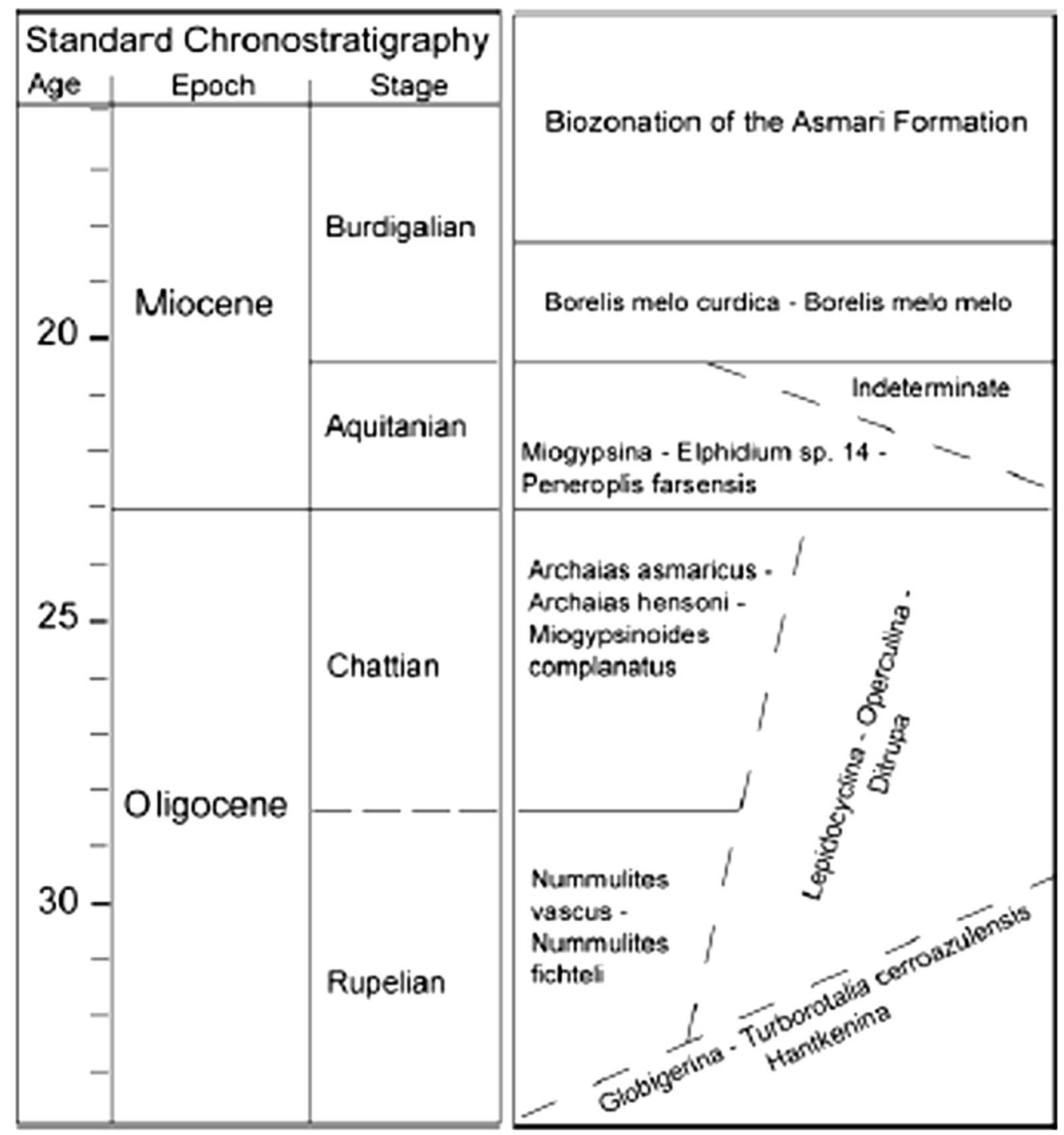

Fig. 6 The newest biozonation of the Asmari Formation (Laursen et al. 2009) 
Fig. 7 Cluster diagram of identified benthic foraminifera in the studied area

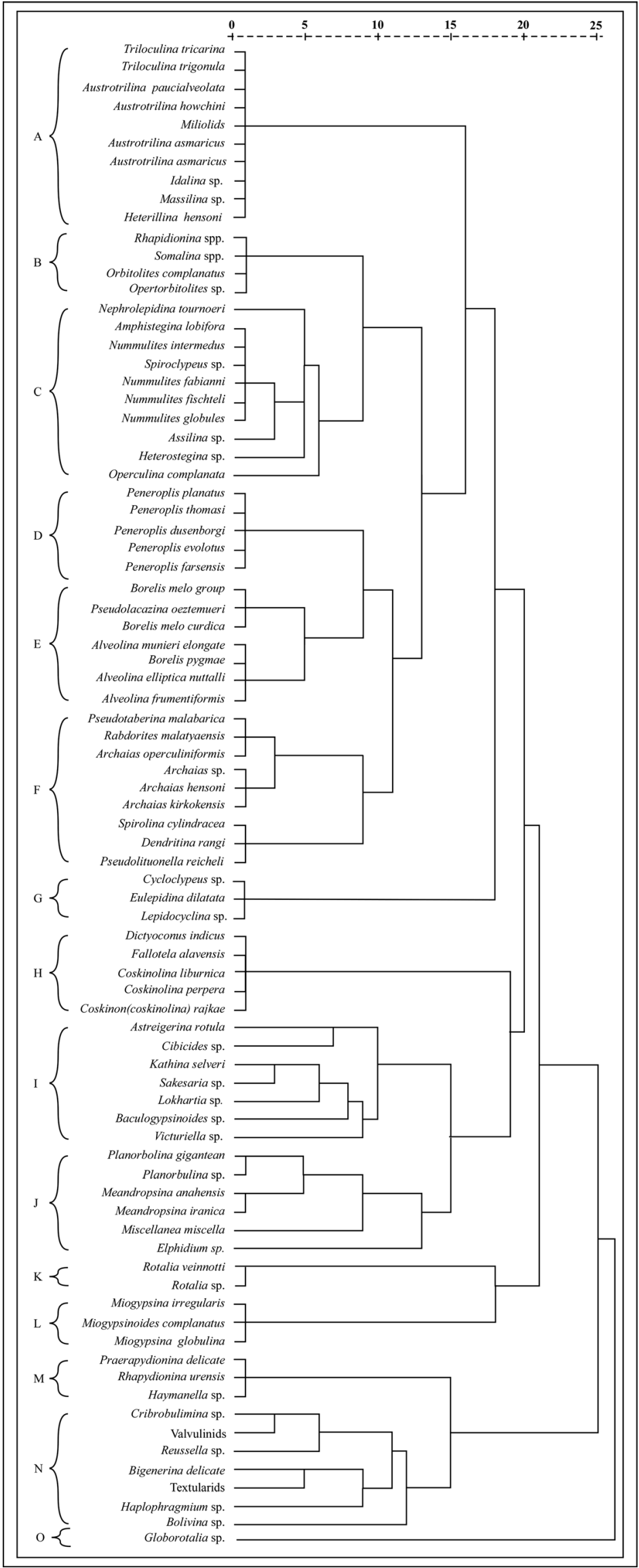




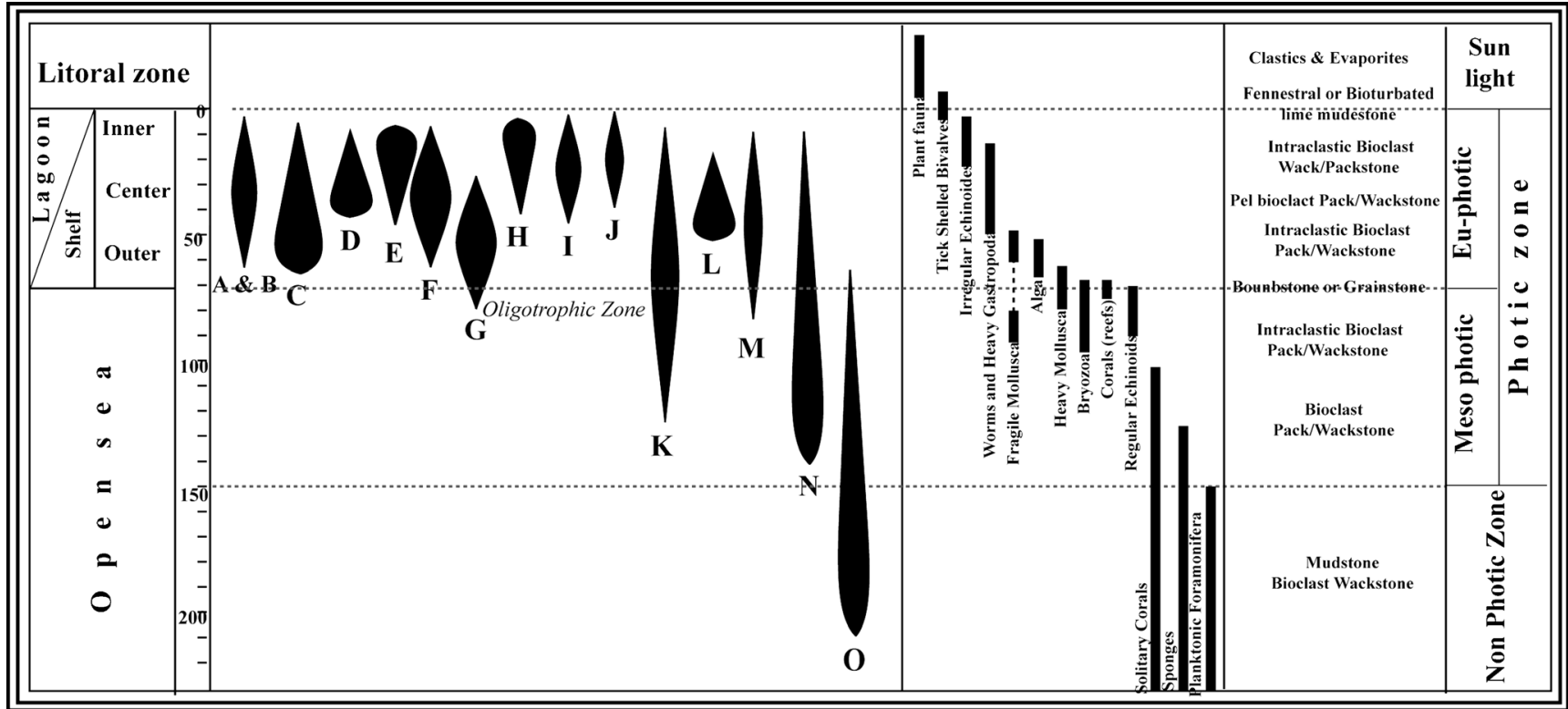

Fig. 8 Biotic ranges of foraminiferal communities and coexisting macrofauna and microfacies in Jaein section

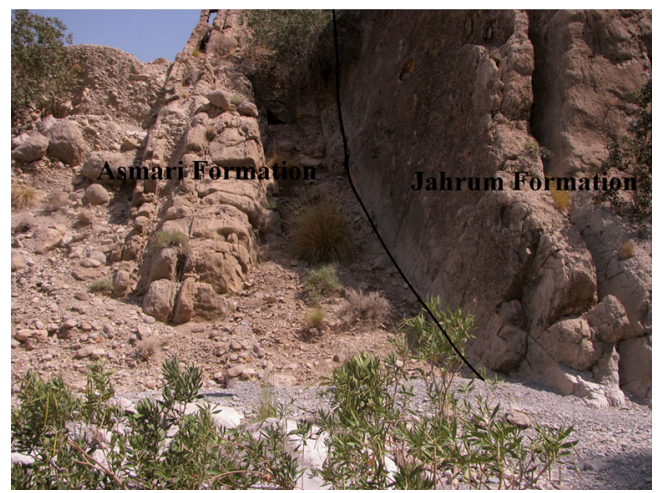

Fig. 9 Conform transition between Jahrum and Asmari formations in Jaein section 


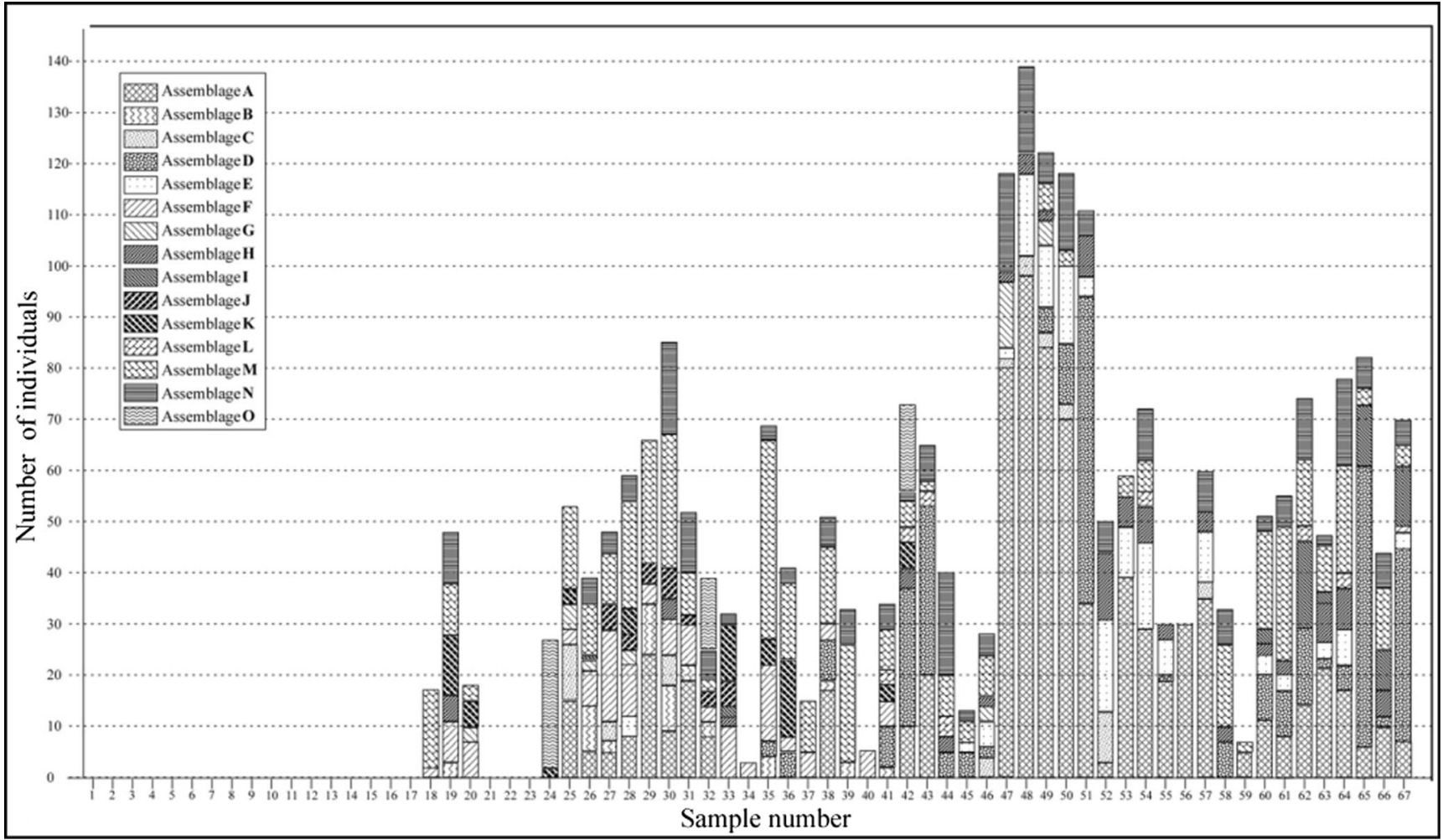

Fig. 10 Distribution of foraminiferal communities along with the Jaein section 


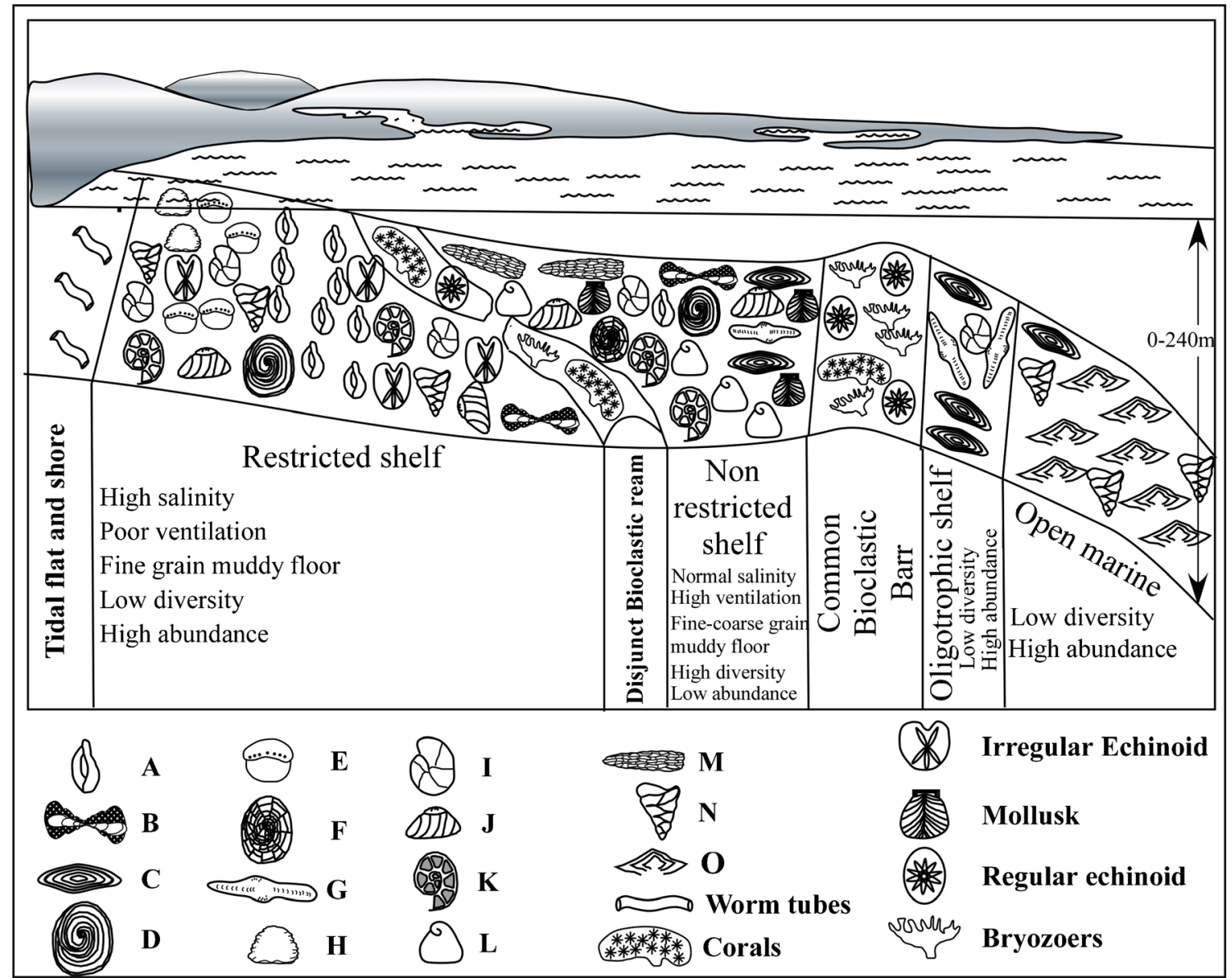

Fig. 11 Paleoecologycal model for the Jaein Section based on presence of foraminiferal assemblages 
Plate 1 1.Nummulites

intermedus, 2, 3.Alveolina

aragonensis, 4. Coskinilina aegeptiensis, 5. Alveolina oblonga, 6. Buccologpsinoides sp., 7. Somalina Stefani,

8. Eulepidina dilatata,

9. Elphidum sp. 10. Lokhartia sp. 11. Katina sp

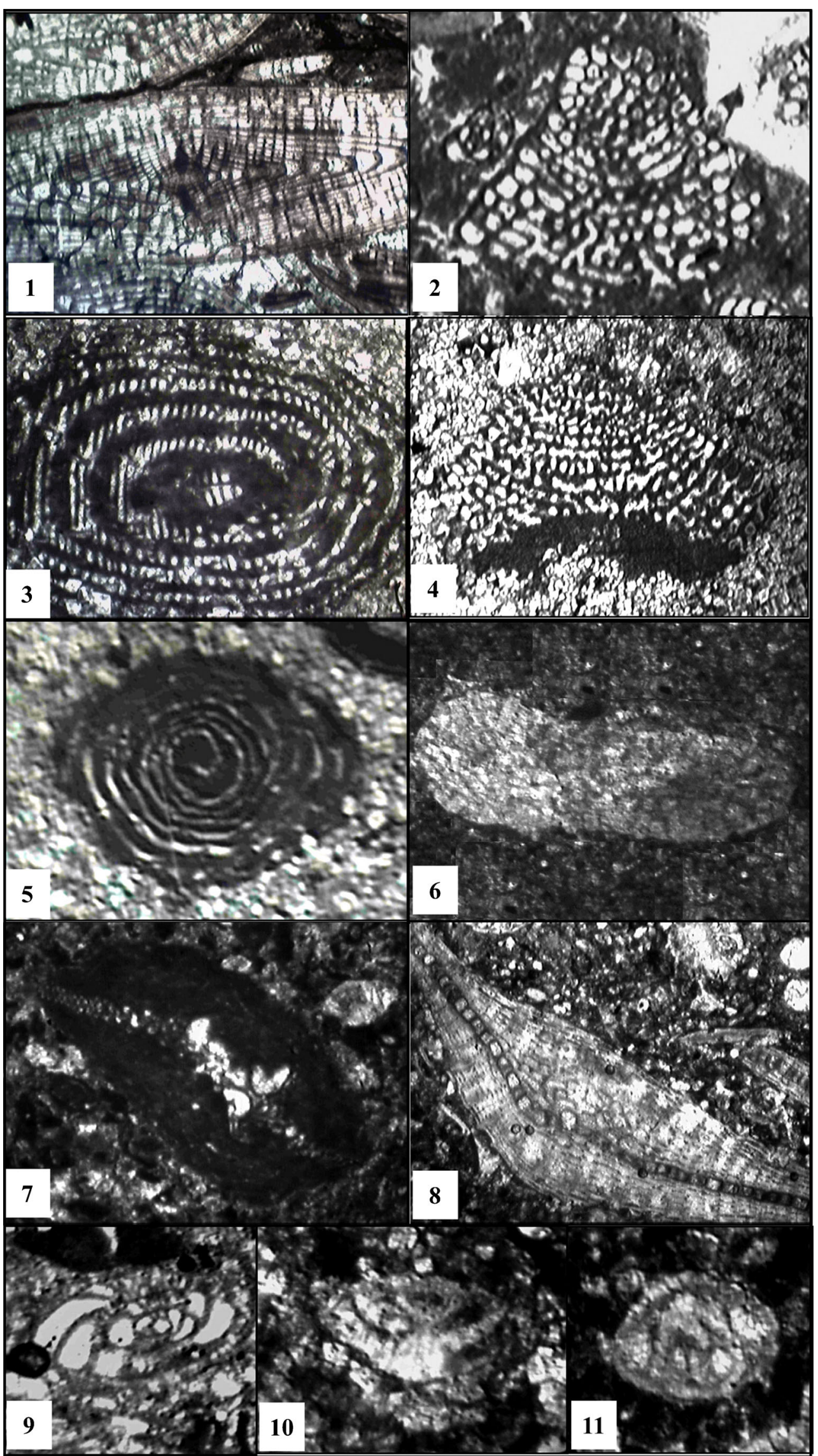


Plate 2 1. Prerapidionina delicate, 2. Nummulites gr. Perforates, 3. Peneroplis planatus, 4. Rotalia viennotti, 5. Nummulites fishtelli,

6. Eulepidina elephantine,

7. Pseudolithoenella reichelli,

8. Alveolina sp., 9. Orbitolites complanatus

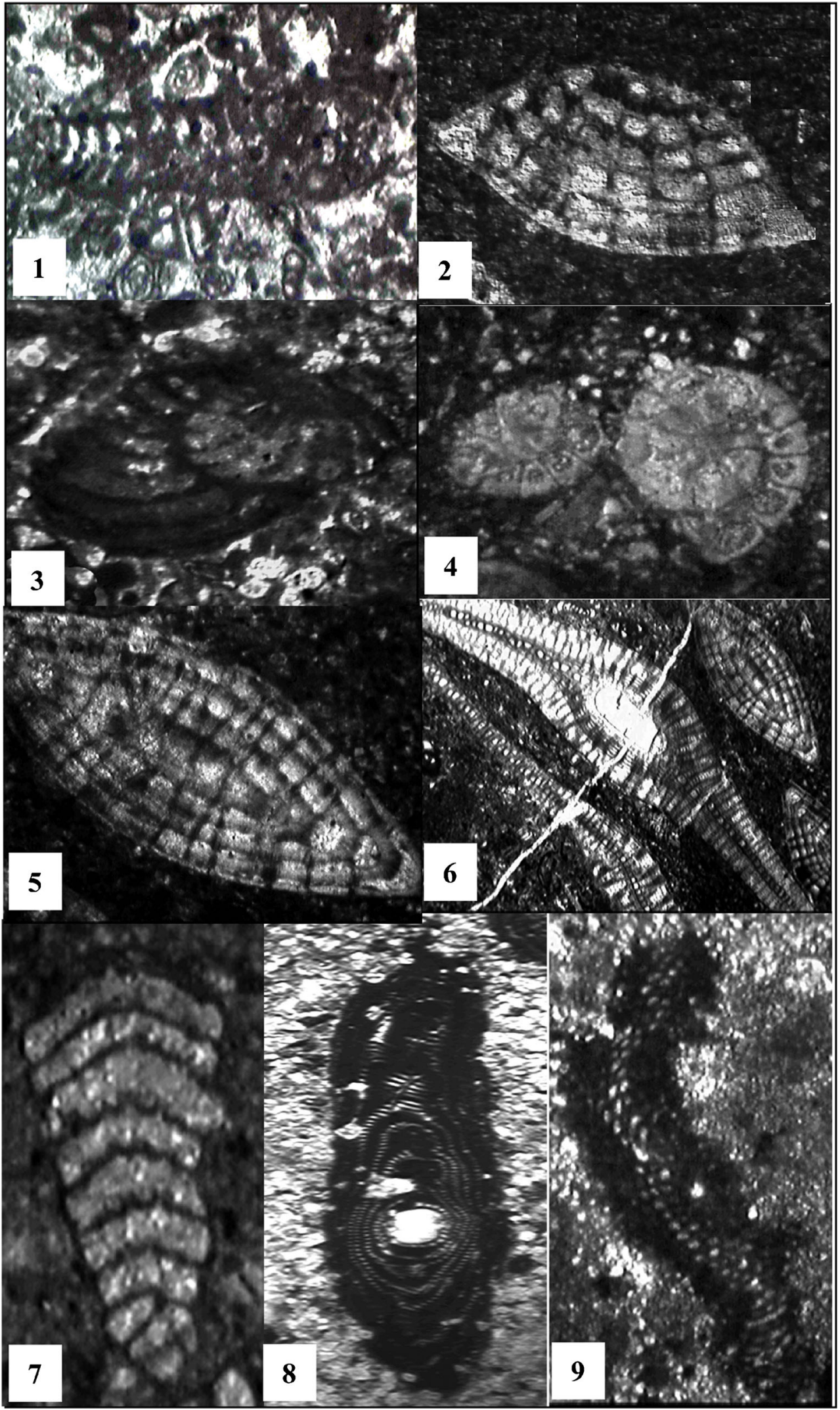


Plate 3 1. Alveolina fromentiformis, 2. Nummulites vascus. 3. Nummulites fabiani, 4. Alveolina eleptica,

5. Nummulites smouthi,

6. Glumalveolina sp.,

7. Coskinolina liburnica,

8. Micellina micela, 9. Lokartia sp., 10. Pellatispira sp.,

11. Alveolina stercasmuris,

12. Tuberina mallabarica

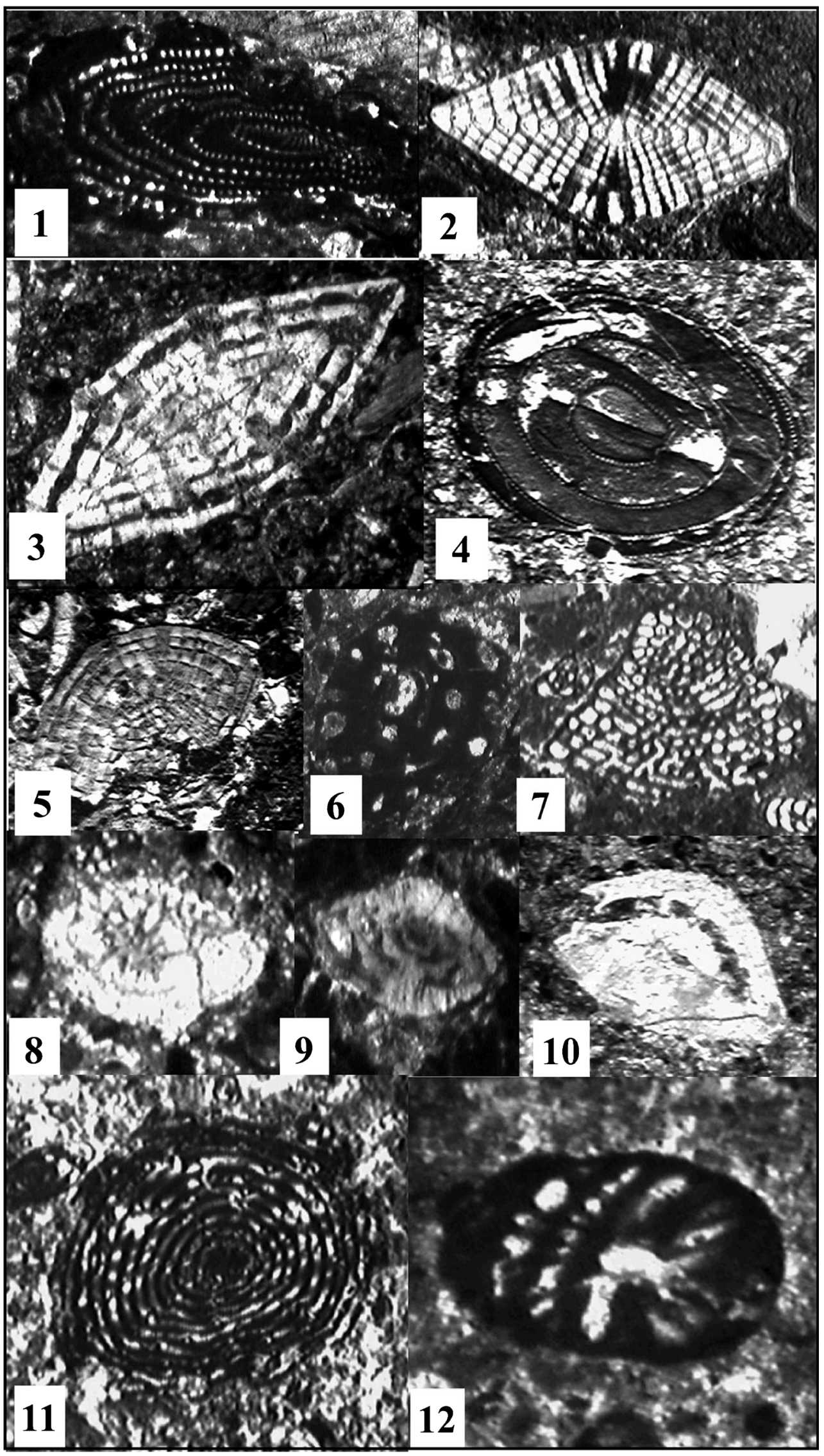

